\title{
Education on prescribing for older patients in the Netherlands: a curriculum mapping
}

\author{
Carolina J. P. W. Keijsers • Johanna E. de Wit • Jelle Tichelaar • \\ Jacobus R. B. J. Brouwers • Dick J. de Wildt • \\ P. G. M. de Vries • Paul A. F. Jansen
}

Received: 16 December 2014 / Accepted: 8 February 2015 / Published online: 11 March 2015

(C) Springer-Verlag Berlin Heidelberg 2015

\begin{abstract}
Purpose Pharmacology and pharmacotherapy education is being increasingly integrated in medical curricula, which might lead to a specific loss of knowledge in these subjects. This, in turn, could lead to harmful prescribing errors, especially in vulnerable older patients.

Methods Teachers who coordinated education in Dutch medical schools completed a structured interview on (geriatric) pharmacology and pharmacotherapy education.
\end{abstract}

Electronic supplementary material The online version of this article (doi:10.1007/s00228-015-1830-2) contains supplementary material, which is available to authorized users.

\section{J. P. W. Keijsers $(\square)$}

Department of Geriatric Medicine, Jeroen Bosch Hospital, PO Box 90153, 5200 ME 's-Hertogenbosch, The Netherlands

e-mail: k.keijsers@jbz.nl

C. J. P. W. Keijsers · J. E. de Wit • J. R. B. J. Brouwers •

P. A. F. Jansen

Department of Geriatric Medicine and Expertise Centre

Pharmacotherapy in Old Persons, University Medical Centre Utrecht,

Utrecht, The Netherlands

C. J. P. W. Keijsers · J. Tichelaar

Education Committee/Working Group Research in Education of the Dutch Society of Clinical Pharmacology and Biopharmacy

(NVKF\&B), Utrecht, The Netherlands

J. Tichelaar • P. G. M. de Vries

Department of Internal Medicine, Section Pharmacotherapy and

RECIPE (Research \& expertise Centre in Pharmacotherapy

Education), VU University Medical Centre,

Amsterdam, The Netherlands

D. J. de Wildt

Department of Translational Neurosciences and Pharmacology, University Medical Centre Utrecht, UMC Utrecht,

Utrecht, The Netherlands
A list of core learning goals was developed. Pharmacology and pharmacotherapy education in general was compared to geriatric pharmacology and pharmacotherapy education. Results All Dutch medical schools participated. Contact hours for education in pharmacology and pharmacotherapy ranged from 39 to $107 \mathrm{~h}$; ECTSs (representing 28 study hours) ranged from 0 to 3 . The various curricula covered, on average, $79 \%$ of all learning goals for these subjects: knowledge $85 \%$, skills $76 \%$, and attitudes $66 \%$; the curricula also covered specific geriatric goals: knowledge $87 \%$ and skills $65 \%$. All geriatric learning goals were met if a geriatrician was among the coordinators. Half (4 of 8 ) of the medical schools lacked appropriate assessment procedures. Evaluation was mostly based on students' opinions. Teachers rated students as being moderately well prepared for daily practice.

Conclusions There are large differences in the quantity and quality of (geriatric) pharmacology and pharmacotherapy education in Dutch medical schools. In general, more time should be devoted to skills and attitude, and the assessment procedures should be optimized with high priority. Other curricula with a problem-based approach might benefit from the points of improvement described in this article.

Keywords Pharmacology · Pharmacotherapy · Geriatric · Curriculum mapping $\cdot$ Learning goals

\section{Introduction}

Medical education has changed in the last decades. Since the 1970s, problem-based learning (PBL) with integrated 
education has gradually become the standard in medical education worldwide [1]. These changes have improved the clinical performance of students during and after graduation and increased student satisfaction [1,2]. However, there is also ongoing debate about the potential disadvantages of PBL, such as a loss of knowledge of basic sciences [1-3], and especially in pharmacology and pharmacotherapy [4]. Studies of drug safety have shown that the number of prescribing errors is high, which could adversely affect patient outcomes, leading to hospitalization or even death $[5,6]$. An estimated $30 \%$ of these errors can be attributed to insufficient knowledge and skills on the part of prescribers [7]. Medical students tend to copy the drug treatment choices of their teachers during clinical clerkships instead of basing their choices on their own independent analysis of the problem [8], which might be why junior doctors feel that they are not adequately prepared to prescribe after graduating [9]. Frail older people are at highest risk of prescribing errors because they often have multiple medical conditions for which they receive polypharmacy [6]. The relative number of older people will continue to increase as the life expectancy increases, and so in the future, most physicians will have to prescribe for these individuals. For this reason, all future prescribers should receive adequate training in prescribing for patients with multiple comorbid conditions and polypharmacy.

However, there is little evidence-based education regarding geriatric pharmacology and pharmacotherapy. In fact, a literature review could not advise a specific educational intervention [10], although the WHO six-step method for rational prescribing is effective in the short and longer term [11-13]. There is still discussion about whether undergraduate curricula provide medical students with enough knowledge to prevent harm and negative patient outcomes. In 1994, Walley et al. found that most curricula ( $89 \%$ ) of UK medical schools had a traditional format with pharmacology and pharmacotherapy given as separate courses, followed by specific assessment of the content of the courses [14]. In 2009, O'Shaughnessy et al. found large differences between UK medical schools in the content, learning strategies, and assessment procedures of curricula. In most medical schools, pharmacology and pharmacotherapy education was integrated vertically and/or horizontally [15]. However, given that most medical schools are still changing their curricula, these studies are probably out of date.

We performed the current curriculum mapping study of training and education in pharmacology and pharmacotherapy, with emphasis on prescribing for older people, provided by Dutch medical schools, with a view to gaining insight into the content, teaching and learning strategies, assessment, and evaluation procedures.

\section{Methods}

Design

This was a cross-sectional observational study of the general and geriatric pharmacology and pharmacotherapy education given in Dutch medical schools, during the academic year 2012-2013. The curricula were studied by means of structured interviews.

\section{Domain}

All eight medical schools of the Netherlands with regular curricula participated. Two medical schools also offer shorter 4year medical courses with a bachelor degree in a biomedical science as entry requirement instead of a secondary school degree. The curricula of these medical courses were not included because they are not comparable with the other curricula. In the Netherlands, all coordinators of (geriatric) pharmacology and pharmacotherapy education at medical schools were asked to participate. They are all members of the Dutch Society of Clinical Pharmacology and Biopharmacy (NVKF\&B).

\section{Instrument: structured interview}

A structured interview on the domains content, teaching and learning strategies, assessment, and evaluation was developed for this study, based on the literature on curriculum mapping [16]. Items were classified by quantity and quality. Quantity was defined as the number of contact hours, the number of European Credit Transfer System (ECTS, $1 \mathrm{~h}$ represents a 28-h student workload), the number of learning goals taught, and the number of full-time equivalent (FTE) teachers. Because self-study hours can vary largely, these were not included. Quality of the education was studied by determining whether there were procedures for assessment and evaluation and by self-assessment, with coordinators being asked "to what extent does the curriculum prepare medical students for their future tasks as prescribers." High quantity scores, high quality, or innovative teaching practices are described in more detail and are considered "best practices."

List of core learning goals

The national blueprint for medical education "het Raamplan" was searched for pharmacology and pharmacotherapy learning goals, especially with reference to older people [17]. Although five items were identified, none referred to older people, and so we considered the national blueprint inadequate for our study goal. For this reason, we searched PubMed for articles on the core curriculum content of pharmacology and pharmacotherapy, using the terms "pharmacology" OR "pharmacotherapy" OR "prescribing" AND "curriculum" with synonyms. A total 
of 1354 hits yielded nine articles. After the addition of (inter)national report by grey search online, ten articles and eight reports were used as sources for learning goals. All goals mentioned at least twice were included in a final list of 47 core learning goals, divided into the categories knowledge, skills, and attitude, shown in Table 1 [18]. A detailed list is shown in Appendix, which includes subheadings and references. This detailed list was used in the interviews.

Table 1 List of core learning goals derived from literature divided by category

\begin{tabular}{|c|c|c|}
\hline Category & Knowledge/skills/attitudes & Learning goals $(n=47)$ \\
\hline Basic pharmacology $(n=4)$ & Knowledge: basic & $\begin{array}{l}\text { Introduction to pharmacology and therapy } \\
\text { Pharmacodynamics }{ }^{\mathrm{a}} \\
\text { Pharmacokinetics } \\
\text { Intra-individual variance and pharmacogenetics }\end{array}$ \\
\hline Clinical pharmacology $(n=15)$ & Knowledge: application & $\begin{array}{l}\text { Adherence, compliance and concordance } \\
\text { Therapeutic drug monitoring } \\
\text { Adverse drug reactions }^{\mathrm{a}} \\
\text { Drug interactions } \\
\text { Medication errors } \\
\text { Drug development and regulation } \\
\text { Medicines management } \\
\text { Evidence based prescribing } \\
\text { Ethical and legal aspects of prescribing } \\
\text { Prescribing for patients with special requirements } \\
\text { (expect older patients) } \\
\text { Rational prescribing } \\
\text { Clinical toxicology } \\
\text { Misuse of drugs } \\
\text { Complementary and alternative medicine } \\
\text { Use of antibiotics and antibiotic resistance }\end{array}$ \\
\hline Geriatric pharmacology $(n=7)$ & Knowledge & $\begin{array}{l}\text { Altered physiology in old people } \\
\text { Altered pharmacokinetics in old people } \\
\text { Altered pharmacodynamics in old people } \\
\text { Different response in frequent used drugs in old people } \\
\text { Principles that underlie prescribing in old people } \\
\text { Polypharmacy } \\
\text { Finding relevant information on drug and dose } \\
\text { adjustments }\end{array}$ \\
\hline Pharmacotherapy $(n=13)$ & Skills & $\begin{array}{l}\text { Medication history taking } \\
\text { Prescribe a new medicine } \\
\text { Calculate drug doses } \\
\text { Prescription writing } \\
\text { Communication } \\
\text { Reviewing prescriptions } \\
\text { Adverse drug reactions } \\
\text { Obtaining information to support rational prescribing } \\
\text { Prescribing high risk medicines } \\
\text { Drug administration } \\
\text { Clinical pharmacokinetics } \\
\text { Prescribing drugs to relieve pain and distress } \\
\text { Drug therapy vs non-drug therapy }\end{array}$ \\
\hline Geriatric pharmacotherapy $(n=4)$ & Skills & $\begin{array}{l}\text { Basic elements of geriatric pharmacotherapy } \\
\text { Avoid potentially harmful drugs } \\
\text { Monitoring medication in old people } \\
\text { Interpret physical, laboratory, and diagnostic test results in } \\
\text { accordance with age related changes }\end{array}$ \\
\hline Medication related attitudes $^{\mathrm{b}}(n=4)$ & Attitude & $\begin{array}{l}\text { Risk-benefit analysis recognition } \\
\text { Recognizing personal limitations in knowledge } \\
\text { Recognition of balanced approach to the introduction of } \\
\text { new drugs } \\
\text { A new prescription as an experiment }\end{array}$ \\
\hline
\end{tabular}

a These five learning goals are also described in the Dutch educational blueprint "het Raamplan"

${ }^{\mathrm{b}}$ No learning goals on geriatric medication related attitudes were found 


\section{Data collection}

Participants from all Dutch medical schools were sent a structured questionnaire before they completed it during an interview with the researchers $\mathrm{CK}$ and $\mathrm{SB}$, who visited the medical schools for this purpose. These interviews, in which the questionnaire was systematically worked through, were taperecorded for completeness; the researchers also took notes during the interview. All participants received their data by e-mail so that they could provide feedback on misunderstandings or misinterpretations and then, after adjustment, to confirm that the data were correct.

\section{Data analyses}

Data were analyzed with SPSS version 22.0. Percentage of learning goals met was calculated as the number of learning goals the curriculum offered divided by the number of learning goals in the core learning goals list (Table 1).

\section{Ethical approval}

The national Ethical Review Board of Medical Education (ERB-NVMO) declared that this study did not involve the data of human subjects.

\section{Results}

All eight medical schools in the Netherlands participated and their 17 coordinators were interviewed in the period of JuneOctober 2013. Table 2 presents the results.

Teaching and learning strategies

All medical schools had a planned curriculum for general and geriatric pharmacology and pharmacotherapy, and all had a more-or-less integrated and problem-oriented curriculum. Four of eight curricula offered pharmacology and pharmacotherapy as a longitudinal learning course throughout the curriculum, with learning activities in different study years. The learning strategies most frequently used were the tutorials, (web)lectures, and elearning. Two e-learning programs have been developed in the Netherlands: Pscribe for rational prescribing and Teaching Resource Centre for pharmacology and applied pharmacology (TRC) [19, 20]. Learning resources clearly differed. Although identical books were often used, at some schools, students mostly relied on practice tests, whereas others mostly used Web lectures on Youtube. All medical schools used the WHO six-step method for prescribing in general [12].
Table 2 Summary of results

Domain

Teaching and learning strategies

Curriculum design All less or more integrated and problem oriented

Teaching strategy

Dominant strategies:

- Tutorials

- (web) lectures

- E-learning

Learning course throughout curriculum: 4/8 medical schools

WHO- six step: $8 / 8$ medical schools

Study materials Most frequently: books

Content

Contact hours

ECTS

Learning goals

Assessment procedures

Mean 71 (SD \pm 25 , range 39-107)

Mean $1.0(\mathrm{SD} \pm 1.2$, range $0-3)$

Compared to Dutch Blueprint:

$90 \%(\mathrm{SD} \pm 15 \%)$

Compared to core list (Table 1 and Appendix 1)

Pharmacology knowledge: $85 \%$ $(\mathrm{SD} \pm 12 \%)$

Pharmacotherapy skills: $76 \%$ (SD $\pm 19 \%$ )

Pharmacotherapy attitudes: $66 \%$ $(\mathrm{SD} \pm 33 \%)$.

Geriatric pharmacology

knowledge: $88 \%(\mathrm{SD} \pm 30 \%)$

Geriatric pharmacotherapy

skills: $66 \%(\mathrm{SD} \pm 27 \%)$

4/8 medical schools offer separate assessments

$4 / 8$ medical schools offer only integrated assessments

(without summative goals)

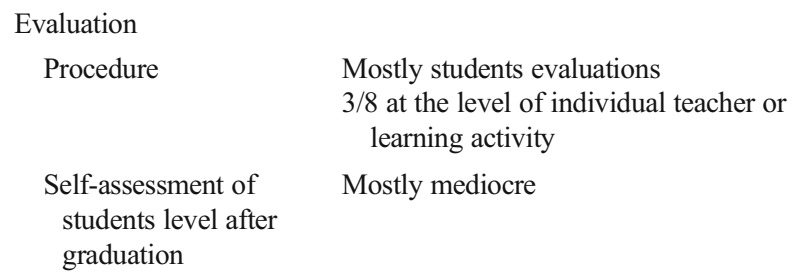

Quantity

Contact hours and ECTS The number of contact hours assigned to pharmacology and pharmacotherapy education varied among schools (mean $71 \pm 25 \mathrm{~h}$, range 39-107 h). Subdivisions over the different topics could not be made, due to the integrated design of the educational program. Few credit points were specifically awarded for pharmacology or pharmacotherapy education (0-3 ECTS, mean $1.0(\mathrm{SD} \pm 1.2)$ ).

Learning goals Overall, the coordinators thought that on average, 37 of the $47(79 \% \mathrm{SD} \pm 15 \%)$ core learning goals 
would be met by the time students graduated, but there were differences between the medical schools regarding which goals would be met (Table 2).

FTE available The number of FTE available for the coordination of education and training could not be compared because the medical schools used different financial systems. For example, in some schools, FTE covered only the coordination of education, with extra FTEs being awarded for teaching activities, whereas other schools considered the FTEs for coordination to include all activities.

\section{Quality}

Assessment Half of the medical schools (4/8) explicitly assessed students' pharmacology and pharmacotherapy knowledge and skills. At the other schools, assessment of this knowledge was integrated in other exams.

Evaluation structure Three medical schools had an evaluation cycle specified by learning activity and teacher, usually based on student evaluations. While the other medical schools also had evaluation cycles, these were tightly integrated, so it was difficult to identify specific activities that could be improved.

Self-evaluation The teachers/coordinators thought that medical students were moderately well prepared for their future tasks as prescribers.

Best practices Dutch medical schools adopt different practices to optimize and monitor training and education. Two medical schools met more than $90 \%$ of the learning goals given in Table 1. Both schools had a clear matrix of learning goals that should be reached at a given time in the curriculum; the two schools had an average number of contact hours. At the medical schools where a geriatrician was part of the coordination team, all learning goals for geriatric pharmacology and pharmacotherapy were met. Newly developed learning methods had been introduced to all medical schools, such as Web lectures on Youtube, two e-learning programs Pscribe and TRC, and the patient letter (an information letter for the patient after discharge with an explanation of changes to their medication list). Four medical schools had a longitudinal learning program throughout the curriculum. With regard to assessment, one medical school had a form of continuous assessment: The test scores for pharmacology and pharmacotherapy were collected throughout medical training, and students could only graduate if their summed score was adequate. Another medical school used a "prescribing Observed Structured Clinical Examination (OSCE)" to assess the students' knowledge and skills in a real-life clinical setting [21]. The other medical schools mostly relied on written assessments. Two medical schools were involved in research in pharmacology and pharmacotherapy education.

\section{Discussion}

There are large differences in the quantity and quality of (geriatric) pharmacology and pharmacotherapy education in Dutch medical schools. Although, generally spoken, the curricula are designed quite well, some points should be addressed. The number of curriculum learning goals that were met was quite acceptable for knowledge items (85\%); this was not the case for skills and attitude, and geriatric skills in particular (up to $66 \%$ ). Teachers rated their own students as being only moderately well-prepared for their careers after graduation. Only half of the schools assessed the knowledge, skills, and attitude of their students before graduation.

Are these findings relevant to patient care? Medicationrelated patient safety is currently a hot topic in research, given the increase in the number of reports of the harmful effects of, often preventable, medication errors and particularly in older patients $[4,22]$. Investigators mention that prescribing knowledge and skills will improve if education and training are improved [4, 23]. Because curricula tend to focus on pharmacology knowledge instead of skills and attitudes, medicationrelated errors may occur. This is in contrast with the general notion that knowledge is a prerequisite for safe prescribing [23] and that the current curricula have a greater focus on skills and attitude than more traditional curricula [2]. It is promising that the WHO six-step method, which has proven to be effective, has been adopted by all Dutch medical schools $[11,13,24]$. Moreover, in general, it is best to provide education throughout medical training, with emphasis on the patient-related context [25-27]. The curricula of all the medical schools in this study offered this integrated, patientoriented approach. Taken together, both the six-step method and integrated education are evidence-based principles that can form the basis from which to improve curricula worldwide.

But, what are the major points for improvement identified in this study? And to what extend can these points of improvement be applied internationally? Although prescribing without a "prescribing exam" is like driving without a driving license, pharmacology and pharmacotherapy skills and knowledge were assessed in only half of the medical schools. Hence, a major point for improvement is the assessment procedure, which may also improve learning efficiency [28]. In earlier studies, this loss of the explicit assessment procedure was already described for the UK after the introduction of the PBL $[14,15]$. Internationally, PBL or related teaching strategies are now the main teaching strategy in medical education [29], although another study describes that PBL introduction depends on culture and that on average, southern European countries 
had lower percentages of medical schools with PBL, at least in 2008 [30]. Given the fact that the loss of explicit assessment procedures of pharmacology and pharmacotherapy is mostly the result of the introduction of PBL [31], it is likely that this point for improvement is applicable to all medical schools with PBL as dominant teaching strategy internationally. Another suggestion is to give more emphasis to the acquisition of skills and attitude and in particular geriatric pharmacotherapy skills. While knowledge is certainly needed as a solid basis, safe prescribing is a skill and requires the right attitudes [23]. It is difficult to assess skills and attitude authentically, but two medical schools use an OSCE and a patient information letter to assess these skills [21]. These strategies would also be suitable for international application in our opinion. The core learning goals presented in this study are based on international literature. These could be used as a test matrix, an overview of topics to be addressed in curricula, in order to optimize both the curriculum design as the assessment procedures. Moreover, because in the Netherlands, all coordinating teachers are united in the Dutch Society of Clinical Pharmacology and Biopharmacy (NVKF\&B), which has regular meetings, and a platform for improvement at a national level is available. As far as we know, such a platform and national cooperation on education is unique, and this successful concept might be replicated in other countries.

Although the results of this study involving all Dutch medical schools offer unique insights, they should be interpreted with appropriate caution. Perhaps the major limitation is our national approach, which decreases the generalizability of our findings to other settings. However, face-to-face contact is the only way to gain real insight into medical education and training. We spent an estimated $8 \mathrm{~h}$ per medical school. Findings would probably be more general or superficial if we had participated in an international study. We might have introduced bias by using an interview design. Furthermore, it is possible that students are offered other learning activities within the integrated curriculum but which are outside the mandate of the curriculum coordinators, a so-called hidden curriculum [32]. We also did not include self-study hours, which vary per student. However, as these aspects are probably uniform to all the medical schools, we think that self-report bias was minimized. We only assessed certain aspects of education quality and did not investigate student satisfaction. The experienced or learned curriculum may differ substantially from the offered and planned curriculum, which was studied in this article [16]. UK medical students feel unprepared after graduation [9], and two other studies confirm a lacking self-confidence for two of the medical schools in this study $[13,33]$. It should be noted that the correlation between self-reporting confidence and performance appeared week [33]. Next to that the coordinators were of the opinion that the students were moderately well prepared for their prescribing tasks.

\section{Conclusion}

This study indicates that, in general, Dutch medical curricula are well constructed, although improvements could be made. These improvements might be applicable to other PBLoriented curricula worldwide. The WHO-6-step method and the integrated, patient-oriented approach are generally believed to be effective for pharmacology and pharmacotherapy education. This study adds to that (1) more attention should be paid to general and geriatric pharmacotherapy skills and attitude so that after graduation, junior doctors should have good prescribing skills for patients of all ages, including the frail elderly. (2) It would be appropriate to evaluate students' prescribing skills before graduation in a "prescribing exam, " preferably in a real-life clinical setting. (3) The core learning goals presented in this study can be used to optimize the curriculum including the assessment procedures. Above points of improvement can contribute to adequate training in good prescribing practice by the time students graduate.

Acknowledgments The authors would like to thank all curriculum coordinators who participated in this study and approved the use of the data in the manuscript: Prof. Dr. Sophia EJA de Rooij (University of Amsterdam), Dr. WMC (Mieke) Mulder (University of Amsterdam), Prof. Dr. Arnold G Vulto (Erasmus University), Dr. Nicole GM Hunfeld (Erasmus University), Dr. JeroenHassink (Erasmus University), Dr. Robert Rissmann (Leiden University), Dr. Marleen HM Hessel (Leiden University), Dr. Ben Janssen (University Maastricht), Adriaan BD van Doorn (University of Groningen), Dr. Itte de Waard-Siebinga (University of Groningen), Dr. Kees Kramers (Radboud University Nijmegen), Dr. Bas Schouwenberg (Radboud University Nijmegen), Dr. TB Yves Liem (University of Utrecht), and Dr. Benjamin Drukarch (VU University Medical Centre).

The authors would like to thank the other members of the Education Committee/working group Research of the Dutch Society of Clinical pharmacology and Biopharmacy (NVKF\&B) for their contribution in the design of the study: Dr. Milan C. Richir (VU University Medical Centre) and Dr. Floris H.M. van Molkot (University Maastricht).

The authors would like to thank Sascha Bosman, medical student, who participated in the data collection.

Sources of support Expertise Centre Pharmacotherapy in Old Persons (EPHOR) is funded by The Netherlands Organisation for Health Research and Development (ZonMw, project number 11.310.4001)

Declaration of interest All authors have completed the Unified Competing Interest form at www.icmje.org/coi_disclosure.pdf (available on request from the corresponding author). Prof. Dr. Brouwers reports personal fees from Consultancy Europe-ExproMuenchen[Germ], personal fees from Consultancy Eijkman \& Kuipers [NL], personal fees from Consultancy W-Pharma Wavre [B], personal fees from President Ethical Review Board, personal fees from Pharmaceutischweekblad, personal fees from Tijdschr v Prakt. Farmacotherapie MFM, grants from St. Ondersteuningsfonds Ephor, all outside the submitted work. All other authors declare no support from any organization for the submitted work, no financial relationships with any organizations that might have an interest in the submitted work in the previous 3 years, and no other relationships or activities that could appear to have influenced the submitted work. 
Funding EPHOR is funded by the Netherlands Organisation for Health Research and Development (ZonMw, project number 11.310.4001) in the Netherlands (www.zonmw.nl). The sponsor did not have any role in the design and conduct of the study, collection, management, analysis, interpretation of the data, review or approval of the manuscript, and decision to submit the manuscript for publication.

Contribution of author statement PJ and CK had full access to all the data and take responsibility for the integrity of the data and the accuracy of the data analysis.

Study concept and design: Keijsers, de Wit, Tichelaar, de Vries, de Wildt, Brouwers, and Jansen.

Acquisition of data: Keijsers and Bosman

Analysis and interpretation of data: Keijsers and Tichelaar

Drafting of the manuscript: Keijsers

Critical revision of the manuscript for important intellectual content:

Tichelaar, de Wit, de Wildt, Brouwers, Jansen, and de Vries

Obtained funding: Brouwers and Jansen

Administrative, technical, or material support: Jansen

Study supervision: De Wildt, Brouwers and Jansen

\section{References}

1. Neville AJ (2009) Problem-based learning and medical education forty years on. A review of its effects on knowledge and clinical performance. Med Princ Pract 18(1):1-9

2. Smits PB, Verbeek JH, de Buisonje CD (2002) Problem based learning in continuing medical education: a review of controlled evaluation studies. BMJ 324(7330):153-156

3. Keijsers CJ, Custers EJ, ten Cate OT (2009) A new, problem oriented medicine curriculum in Utrecht: less basic science knowledge. Ned Tijdschr Geneeskd 153:B400

4. Members of EMERGE,Erice Medication Errors Research Group, Agrawal A, Aronson JK, Britten N, Ferner RE, de Smet PA et al (2009) Medication errors: problems and recommendations from a consensus meeting. Br J Clin Pharmacol 67(6):592-598

5. Krahenbuhl-Melcher A, Schlienger R, Lampert M, Haschke M, Drewe J, Krahenbuhl S (2007) Drug-related problems in hospitals: a review of the recent literature. Drug Saf 30(5):379-407

6. Leendertse AJ, Egberts AC, Stoker LJ, van den Bemt PM, HARM Study Group (2008) Frequency of and risk factors for preventable medication-related hospital admissions in the Netherlands. Arch Intern Med 168(17):1890-1896

7. Lesar TS, Briceland L, Stein DS (1997) Factors related to errors in medication prescribing. JAMA 277(4):312-317

8. Tichelaar J, Richir MC, Avis HJ, Scholten HJ, Antonini NF, De Vries TP (2010) Do medical students copy the drug treatment choices of their teachers or do they think for themselves? Eur J Clin Pharmacol 66(4):407-412

9. Heaton A, Webb DJ, Maxwell SR (2008) Undergraduate preparation for prescribing: the views of $2413 \mathrm{UK}$ medical students and recent graduates. Br J Clin Pharmacol 66(1):128-134

10. Keijsers CJ, van Hensbergen L, Jacobs L, Brouwers JR, de Wildt DJ, ten Cate OT et al (2012) Geriatric pharmacology and pharmacotherapy education for health professionals and students: a systematic review. Br J Clin Pharmacol 74(5):762-773

11. de Vries TP, Henning RH, Hogerzeil HV, Bapna JS, Bero L, Kafle KK et al (1995) Impact of a short course in pharmacotherapy for undergraduate medical students: an international randomised controlled study. Lancet 346(8988): 1454-1457

12. Ross S, Loke YK (2009) Do educational interventions improve prescribing by medical students and junior doctors? A systematic review. Br J Clin Pharmacol 67(6):662-670
13. Keijsers CJ, Segers WS, de Wildt DJ, Brouwers JR, Keijsers L, Jansen PA (2014) Implementation of the WHO-6-step method in the medical curriculum to improve pharmacology knowledge and pharmacotherapy skills. Br J Clin Pharmacol. doi:10.1111/bcp.12575

14. Walley T, Bligh J, Orme M, Breckenridge A (1994) Clinical pharmacology and therapeutics in undergraduate medical education in the UK: current status. Br J Clin Pharmacol 37(2):129-135

15. O'Shaughnessy L (2010) Teaching of clinicalpharmacology and therapeutics in UK medical schools: current status in 2009. Br J Clin Pharmacol 70(1):143-148

16. Harden RM (2001) AMEE Guide No. 21: curriculum mapping: a tool for transparent and authentic teaching and learning. Med Teach 23(2): 123-137

17. Nederlandse Federatie van Universitaire Centra (2009) Raamplan Artsopleiding. Available at: http://www.nfu.nl/img/pdf/Raamplan Artsopleiding_2009.pdf. Accessed Aug 2014

18. Carter C (1985) A taxonomy of objectives for professional education. Stud High Educ 10(2):135-149

19. van Doorn A (2007) The value of a learning content management system (LCMS) for assessment of an internet application programme 'Pscribe' in problem-based pharmacotherapy teaching. Basic Clin Pharmacol Toxicol 101:51-102

20. Franson KL, Dubois EA, de Kam ML, Cohen AF (2008) Measuring learning from the TRC pharmacology E-Learning program. Br J Clin Pharmacol 66(1):135-141

21. Smee S (2003) Skill based assessment. BMJ 326(7391):703-706

22. Kongkaew C, Noyce PR, Ashcroft DM (2008) Hospital admissions associated with adverse drug reactions: a systematic review of prospective observational studies. Ann Pharmacother 42(7):1017-1025

23. Aronson JK, Henderson G, Webb DJ, Rawlins MD (2006) A prescription for better prescribing. BMJ 333(7566):459-460

24. Richir MC, Tichelaar J, Geijteman EC, de Vries TP (2008) Teaching clinical pharmacology and therapeutics with an emphasis on the therapeutic reasoning of undergraduate medical students. Eur J Clin Pharmacol 64(2):217-224

25. Raman M, McLaughlin K, Violato C, Rostom A, Allard JP, Coderre S (2010) Teaching in small portions dispersed over time enhances long-term knowledge retention. Med Teach 32(3):250-255

26. Wijnen-Meijer M, ten Cate OT, van der Schaaf M, Borleffs JC (2010) Vertical integration in medical school: effect on the transition to postgraduate training. Med Educ 44(3):272-279

27. Schwartz A, Weiner SJ, Harris IB, Binns-Calvey A (2010) An educational intervention for contextualizing patient care and medical students' abilities to probe for contextual issues in simulated patients. JAMA 304(11):1191-1197

28. Wood T (2009) Assessment not only drives learning, it may also help learning. Med Educ 43(1):5-6

29. Nara N, Suzuki T, Tohda S (2011) The current medical education system in the world. J Med Dent Sci 58(2):79-83

30. Jippes M, Majoor GD (2008) Influence of national culture on the adoption of integrated and problem-based curricula in Europe. Med Educ 42(3):279-285

31. Maxwell SRJ, Webb DJ (2006) Clinical pharmacology - Too young to die? Lancet 367(9513):799-800

32. Hafler JP, Ownby AR, Thompson BM, Fasser CE, Grigsby K, Haidet $P$ et al (2011) Decoding the learning environment of medical education: a hidden curriculum perspective for faculty development. Acad Med 86(4):440-444

33. Brinkman DJ, Tichelaar J, van Agtmael MA, de Vries TP, Richir MC (2015) Self-reported confidence in prescribing skills correlates poorly with assessed competence in fourth-year medical students. J Clin Pharmacol

34. Maxwell S, Walley T, Ferner RE (2002) Using drugs safely. Br Med J 324(7343):930-931 